\title{
Iterating on Students' Perceptions of Iteration in the Design Process: An Ex- ploratory Study
}

Steven Eric Meyer, Franklin W. Olin College of Engineering

Steven Meyer is studying Mechanical Engineering at Olin College of Engineering. He is an active member of the college's SAE BAJA team.

\section{Dr. Alexandra Coso Strong, Franklin W. Olin College of Engineering}

Alexandra Coso Strong is an assistant professor of systems design and engineering at Franklin W. Olin College of Engineering. Prior to starting a faculty position at Olin, she was a Postdoctoral Fellow at Georgia Tech's Center for the Enhancement of Teaching and Learning. She completed her Ph.D. in 2014 in Aerospace Engineering at Georgia Tech. Alexandra received her B.S. in Aerospace Engineering from MIT and her M.S. in Systems Engineering from the University of Virginia. Her research interests include engineering design education (especially in regards to the design of complex systems), student preparation for post-graduation careers, approaches for supporting education research-to-practice. 


\title{
Iterating on Students' Perceptions of Iteration in the Design Process:
}

\section{An Exploratory Study}

\begin{abstract}
Explorations of experienced designers demonstrate how these designers employ iterative methods to refine their understanding of a problem and to improve their designs. In contrast, many novice designers do not perceive iteration as an important activity within the design process. Yet, novice designers' perspectives of iteration tend to shift after initial design experiences, viewing iteration as one of the most important design activities. Given this shift and the critical role of iteration within design practice, the purpose of this study is to explore iteration more deeply and uncover students' perceptions about how this aspect of design is related to the broader design process. Students within a senior level aerospace engineering design course at a large public university were given an open ended survey prompt to document their design process mid-way through the course. The resulting 70 design processes were explored using an open coding methodology. The resulting set of categories describe how students perceive the role of iteration. Preliminary results show that students perceive iteration explicitly occurring once or not at all during the design process. When iteration did occur, it was most common in the late stages of the process with rare occurrences at the beginning. In addition, the students discussed using iteration to improve the results of mathematical models, as opposed to, for instance, supporting their understanding of the problem. The results of this study demonstrate the need for additional research to explore how iteration is defined and how to support students' understanding of the diverse uses of iteration within design. Recommendations for future research directions are presented in the paper along with implications for design educators who wish to further develop their students' understanding of iteration.
\end{abstract}

\section{Motivation}

Explorations of the experiences of novice and experienced designers have demonstrated critical differences in their approaches to solving design problems ${ }^{1-3}$. Some examples of the differences occur during problem framing, research phases, idea generation, trade-offs analysis, decisionmaking, and reflection on design experiences ${ }^{3}$. For example, as part of problem framing, experienced designers hold off on making decisions until they have had time to diverge and understand the challenge in a more holistic context ${ }^{3}$. In contrast, beginning designers believe design tasks can be straightforward and are relatively easily understood by the list of requirements ${ }^{3}$. Continued research about novice designers' approaches and experiences moving from novice to more experienced designers could support educators that seek to prepare engineering students to be better equipped to tackle complex, multidisciplinary engineering challenges upon graduation.

Many studies have focused on the behaviors of novice and experienced designers as they engage with a design problem or task $\mathrm{k}^{1,2,4,5}$, while fewer have explored these designers' perceptions of the design process and particular design activities ${ }^{6-9}$. To deepen our existing understanding about students' development from novice to more informed or experienced designers, these studies of students' perceptions of their design process allow researchers and practitioners to supplement 
existing knowledge of observable behaviors with rich, sometimes visual, descriptions of students' mental models of engineering design and the related design activities. For example, Atman and colleagues' exploration of students' use of engineering design language ${ }^{8}$ highlights how students have not 'fully internalized the language [of design]' (p. 323). Without this language, it becomes more difficult for students to employ their design knowledge in a new context or for a new design problem. To complement existing research on students' perceptions of the design process and related activities, further in-depth explorations of specific aspects of design are necessary and have the potential to support the creation of new educational approaches to facilitate the development of students as designers.

Iteration is one design activity and term that does not have a consistent definition throughout the literature $^{10}$. For example, Smith ${ }^{11}$ defines iteration as an approach similar to those used in mathematics to obtain a solution to a problem based on a set of assumptions. Another definition given by Wynn and colleagues ${ }^{10}$ describes iteration as an activity that allows trade-offs to occur among various different stakeholders. The role iteration plays in a design process also varies, such as using iteration to refine the understanding of a problem ${ }^{12}$ or as a managerial tool ${ }^{13}$. Although there is little agreement on the definition and function of iteration, researchers and practitioners perceive iteration as important and as an activity that happens early and throughout the design process.

Previous studies have highlighted stark differences between novice and experienced designers' use of iteration within a design process. Experienced designers use iteration to both clarify and attain a better understanding of a problem, usually based on a cyclical feedback loop ${ }^{3}$. On the other hand, novice designers who tend to complete a set process of steps in a linear fashion may leave little room for an iterative process $^{3}$. Since iteration can be a challenge to assess based on a final deliverable ${ }^{14}$, researchers have identified observable behaviors for defining a students' understanding of iteration ${ }^{3}$ as well as designed studies to explore students' perceptions of design activities, including iteration. In particular, research has shown that novices designers do not always see the value of iteration as a design activity ${ }^{15-18}$. Across two studies, over $30 \%$ of students at the start of senior design suggested iteration was one of the least important design activities ${ }^{15,17}$. However, after participating in a scaffolded design experience, these students' perspectives on iteration, and its role in a design process significantly changed ${ }^{15-17}$. For example, in the research done by Hohner and colleagues ${ }^{16}$, approximately $3 \%$ of students initially rated iteration as an important design skill, but after a design activity, over $20 \%$ of students rated it as the most important. These significant changes in perception suggest a need to further examine how novice designers perceive iteration in the context of a design experience. Therefore, the purpose of this preliminary study is to explore iteration more deeply and uncover students' perceptions about how this aspect of design is related to a broader design process.

\section{Methods}

\section{Research Site \& Sample}

The research site for this study was a two-course senior aircraft design experience within the aerospace engineering department at a large public, research institution. Eighty-three students were registered for this year-long senior design sequence, and 70 students consented to 
participate in the research study. Of the 70 students, 7 identified as female (10\%) and 3 were international students $(\sim 4.3 \%)$. Twenty-five students $(\sim 35.7 \%)$ noted having completed a design course at another point in their undergraduate curriculum, while 44 students $(\sim 63 \%)$ described having industry experience, either through a co-op or internship.

The objective of the year-long design course sequence, as defined in the syllabus, is to provide students experience in conceptual design, including integrating methods for vehicle sizing, configuration selection and layout determination, propulsion system design, vehicle performance analysis and cost analysis. The focus of this study is data collected in the first semester of the design sequence. During the first semester, the course instructors introduce students to an aircraft design process and methods for weight sizing and constraint sizing through twice weekly lectures and weekly lab sessions. Students then practice applying these concepts within a series of mini-projects.

\section{Data Collection}

Data was collected during one of the lab sessions in early November. By this point in the semester, the students had exposed to the aircraft design process for 11 weeks and had completed three individual design projects. The lab was designed to serve as a summative experience for the students to revisit the design process and begin to explore a new topic. The lab session design is described in detail in previous work ${ }^{17}$.

The focus of this paper is on the artifacts developed during the initial framing activities within these sessions. In particular, students were asked to describe, visually or with words, the design process they had utilized so far using 23 design activities (see Table 1). This activity list is based on the Design Ranking Test utilized in previous studies to understand the conceptual models students have developed about design ${ }^{6-8,15,16,18,19}$.

The following directions were read aloud to the students and were also displayed visually on a PowerPoint presentation:

Think about the process you have been following in this course so far, use the activities above to describe the different steps in that process. Provide explicit examples where possible: if you write GENERATING ALTERNATIVES as step 3 -add, for example, Search on NACA for different airfoil design alternatives. Feel free to draw, write, and use the sticky notes to describe the design process on the piece of paper distributed.

Table 1: Design Activities List for Prompt

\begin{tabular}{|l|l|l|}
\hline Abstracting & Identifying Constraints & Seeking Information \\
\hline Brainstorming & Imagining & Sketching \\
\hline Building & Iterating & Synthesizing \\
\hline Communicating & Making Decisions & Testing \\
\hline Decomposing & Making Trade-Offs & Understanding the Problem \\
\hline Evaluating & Modeling & Using Creativity \\
\hline Generating Alternatives & Planning & Visualizing \\
\hline Goal Setting & Prototyping & \\
\hline
\end{tabular}




\section{Data Analysis}

To explore how students perceive "iteration" within the context of a design process, the resulting student artifacts depicting their understanding of and perceptions about the aircraft design process were analyzed using an iterative qualitative analysis approach ${ }^{20-22}$. One researcher read through all of the students' design process artifacts (see example in Figure 1) and categorized each response based on the students' use of iteration. After creating an initial list of categories, two researchers discussed the categories in detail, reviewing potential definitions for each category and exploring possible literature sources to provide theoretically-grounded guidance for a set or subset of the categories. Then the two researchers engaged in multiple iterations of analyzing the artifacts and categories and conducting coding comparisons. In particular, one researcher read, and reread, each artifact and the associated categories, modifying the categories by collapsing or expanding them. Then both researchers conducted coding comparisons using a subset of the artifacts, discussing any differences and modifying the definitions of the categories as needed to reach consensus ${ }^{20}$. Finally, one researcher analyzed all of the artifacts using the resulting category list and definitions.

$$
\begin{aligned}
& \text { 1.) Abstracting } \rightarrow \text { what is project about? } \\
& \text { 2.) Identify Constraints } \rightarrow \text { what exuct items do I need to find? } \\
& \text { 3.) Secking Information } \rightarrow \text { vse Roskum etc to find how to get info } \\
& \begin{array}{l}
\text { 1.). Evaluating } \rightarrow \text { use Roskaw infos to solve for constraints [evaluating includes: trade-offs, decision making, } \\
\text { iterating, generating altaradues] }
\end{array} \\
& \text { i.) Testing } \rightarrow \text { ensure all requirements are met } \\
& \text { ) Communicating } \rightarrow \text { write report to show results }
\end{aligned}
$$

Figure 1: Example Student Response

\section{Limitations}

Considering the research design, it is important to keep in mind the limitations inherent in this study. First, the results presented here are based on the analysis of students from a single course within a multidisciplinary engineering department at a large, public institution. Additional research of other engineering disciplines, senior design experiences, and at other institutions could further enrich the results. Within the data collection design, the activities provided to students use terminology viewed as accessible to students; however, the results may be limited based on students' interpretation of this terminology. This instrument was also not explicitly designed to explore iteration exclusively, as a result, it is possible that some students' perceptions were not included within this analysis. Finally, approaches such as documentation of the category development process ${ }^{22}$ and discussions between the two researchers were used to mitigate the impact of potential researcher bias on the results. 


\section{Results}

\section{Instances of Iteration}

The number of instances of iteration was counted within each student's design process. Fifty four responses $(\sim 77 \%)$ contained at least one instance of iteration. A response was considered to contain an instance of iteration if it explicitly used the word iteration or if it linked nonsequential parts of the design process together.

The responses were then grouped into the four following categories: linked, single instance, multiple instances, and continuous instance. Linked iteration consisted of iteration that connected multiple steps of the design process together; these steps were not necessarily sequential (see Figure 2, right image). Responses were coded as single instance when iteration only occurred once, usually as a step or sub-step in the process (see Figure 2, left image). Similarly, multiple instances represented responses which included iteration, either explicitly or with links, multiple times in the design process. These multiple instances of iteration could also be described in separate steps in different sections of the design process. A response was categorized as continuous iteration if iteration was constantly occurring throughout the entirety of the design process. Of students who included iteration as an explicit part of their design process, it was most common for them to include a single instance of iteration $(\mathrm{n}=39, \sim 71 \%)$. A further breakdown of the types of iteration is shown in Table 2 .

Table 2: Instances of Iteration in Student Responses $(\mathrm{n}=54)$

\begin{tabular}{|lll|}
\hline Type of Iteration & Freq. & $\%$ \\
\hline Single & 39 & $\sim 71$ \\
\hline Single, Linked & 6 & $\sim 11$ \\
\hline Multiple & 9 & $\sim 16$ \\
\hline Continuous & 1 & $\sim 2$ \\
\hline
\end{tabular}

$$
\begin{aligned}
& \begin{aligned}
\text { Stepl: Understawding the problem, Seckmy Informatron } \\
\text { - Researching to gain Knowledge of aspects of the RFR }
\end{aligned} \\
& \text { Step 2: Identify.y Constrants } \\
& \begin{aligned}
\text { Step 3: Generathy Alternatues, Brainstorming } \\
\text { Brainstormm alternatwer matrix w/ Figures of merit }
\end{aligned} \\
& \text { Step 4: Evaluating } \\
& \text { - Evaluatims altelizing } \\
& \begin{array}{l}
\text { Step 5: Sketchmy, Visualizing model } \\
\text { - Sketch conceptual model }
\end{array} \\
& \text { Step6: Analyzing, Iteratms model for performance characteristres } \\
& \text { - Analyze concepet RFP requirements } \\
& \text { Step?: }
\end{aligned}
$$

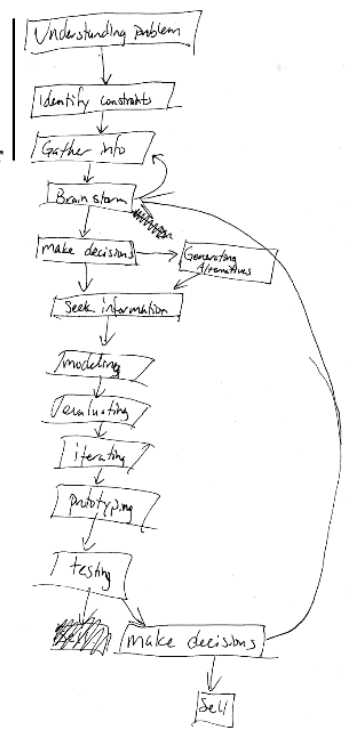

Figure 2: Examples of Student Responses with a single iteration (LEFT) and multiple iterations, including linked steps (RIGHT) 


\section{Timing of Iteration in Overall Design Process}

Students' design processes included iteration at different stages of the process. For analysis purposes the stages were broken down into the first quarter, middle half, last quarter, and multiple times/continuous. The exact determination of when iteration occurred in the design process was dependent on an individual student's design process. For those design processes categorized as multiple times/continuous, there were multiple instances of iteration or iteration occurred throughout the student's design process.

Iteration was found to be utilized most often in the last quarter of the design process ( $\mathrm{n}=29$, $\sim 53 \%$ ). In contrast, there were only 2 instances $(\sim 4 \%)$ that occurred in the first quarter. A further breakdown down of the timing of iteration within students' design processes can be found in Figure 3.

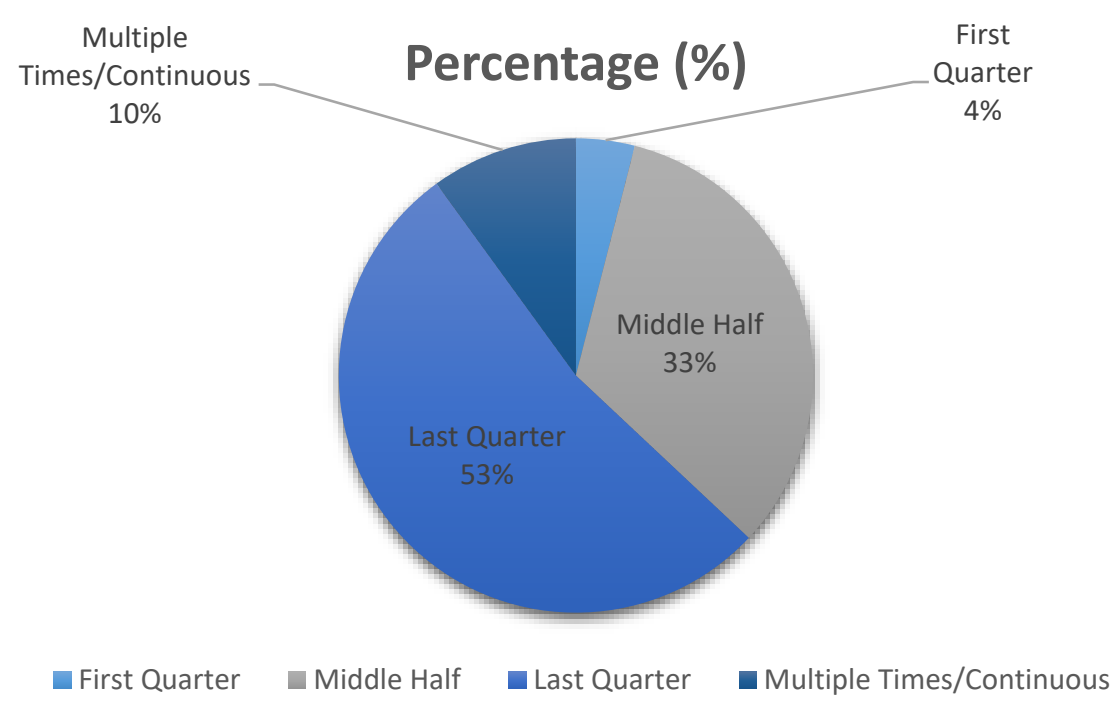

Figure 3: Distribution of Iteration across a Design Process

\section{Student Characterizations of Iteration}

Certain themes emerged from the student-given characterizations of iteration that aligned with existing characterizations from the literature. Wynn and colleagues ${ }^{10}$ presented a framework describing six different types of iteration, from refinement, where a design meets primary requirements but is refined to enhance other characteristics, to exploration, where designers engage in a process of solution space divergence and convergence cycles. Of these existing types, only 3 were seen in the students' responses: convergence, rework, and repetition. Along with these three categories, one other emerged as common types of iteration within these responses and convergence was split to capture two distinct definitions. The resulting categories, converge-value, rework, converge-optimal, repetition, evaluation, and no definition, are defined in Table 3 and the frequency of their use is highlighted in Figure 4. It is important to note that students may have multiple characterizations of iteration within a single design process. As a result, more than one type of iteration may have been used to describe a given student's discussions of iteration. 
Table 3: Iteration Types (Adapted from Wynn, 2007)

\begin{tabular}{|cc|}
\hline Type of Iteration & Definition \\
\hline Converge-Value & $\begin{array}{c}\text { Improve/refine results, such as goal } \\
\text { seeking in Excel }\end{array}$ \\
\hline Converge-Optimal & Finding ideal configuration \\
\hline Rework & $\begin{array}{c}\text { Changes in previous design work, } \\
\text { redirecting to other steps in the process. }\end{array}$ \\
\hline Evaluation & $\begin{array}{c}\text { Repeating specific steps or sequences. } \\
\text { Evaluating and changing decisions } \\
\text { based on new/changing information }\end{array}$ \\
\hline No Definition & No explanation or definition given \\
\hline
\end{tabular}

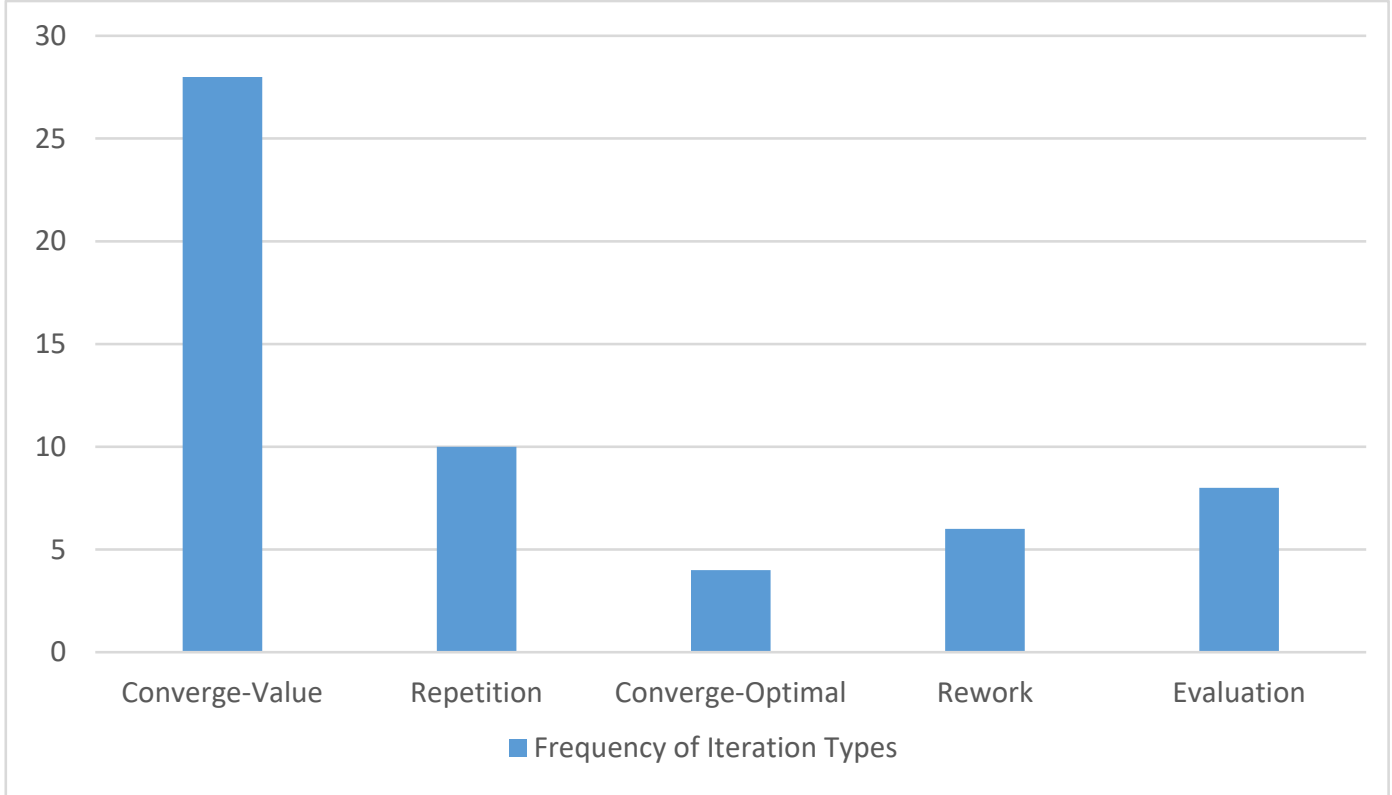

Figure 4: Frequency of Iteration Types

Among responses that contained a particular characterization of iteration, converge-value was the most common with 28 instances. These students viewed iteration as an activity allowing them to improve or refine their design parameters. For example, one student explained that iterating was "[repeating] the modelling (mainly excel based) until the numbers converge to the desired design (or at least close to it)." Another student discussed how iteration started after one guessed initial parameters, "guesses for initial weight were inputted to an iterative sizing process, until this weight matched historical trends. " Finally, students described how iteration would need to occur until they were satisfied with the results. One student said they "iterate until 
I am satisfied with the data for the aircraft, and that it meets the needs of whoever I am designing for."

Other students discussed the idea of iteration as convergence, but a few $(n=4)$ discussed it with a focus on optimization and finding ideal solutions through an iterative process:

- "Iterating: Continued evaluation of decisions made that allow you to see if these are the best possible design components/configurations."

- "When a design is reached, flaws need to be identified and accounted for. The $1^{\text {st }}$ design will never be the final design. Processes need to be iterated in order to develop the best possible solution."

- "Identify best things about designs to optimize design."

Repetition was the second most common characterization of iteration $(n=10)$. These students described iteration as the process of repeating steps. For example, one student explained how iteration means they will "repeat steps \#1-5 for each design problem." Characterizations of iteration as rework were less common $(\mathrm{n}=6)$ and focused on making changes to aspects of the design that were inaccurate. For instance, one student mentioned iterating "if anything (especially assumptions) was not correct earlier, fix/change and iterate." Another student explained that "when a design is researched, flaws need to be identified and accounted for. The first design will never be the final design. Processes need to be iterated in order to develop the best possible solution." Other similar conceptions of iteration also emphasized the use of iteration to fix flaws by repeating steps or redoing work.

The evaluation category emerged from definitions that included analysis of the current state of the design as part of iteration. One student described iterating as "continued evaluation of decision made that allow you to see if these are the best possible design components/configurations." Another student characterized iteration as "[identifying] best things about designs to optimize design." Each of these definitions suggest the need to evaluate one's current design or the related set of assumptions in order to iterate on that design.

\section{Discussion and Implications}

Even with disagreement on the exact role and definition of iteration, experienced designers and researchers perceive iteration as an important activity that occurs early and throughout the design process. The senior engineering students in this study, even after 11 weeks of engagement with conceptual design, tended to have novice conceptions of iteration. Close to one-quarter of the students in this study did not include evidence of explicit iteration in their design process. Contrary to perspectives of iteration included in the literature, iteration was perceived by these students to occur in the later stages of the design process and to only occur once. This perception does not align with the practices of experienced designers who iterate as they frame and structure a design problem ${ }^{3}$. Iteration was also viewed by the students as an activity for converging a mathematical model. This strict definition does not encompass the use of iteration as an opportunity to engage in cycles of idea generation, testing, and redesign, to refine a designer's understanding of the task, or to gain new insights about a solution ${ }^{3,12,23-25}$. 
For engineering design educators, these results suggest a need to design activities where students closely examine their own design work and processes or critique others to expose them to different functions of iteration and different options for when to iterate ${ }^{26,27}$. By creating opportunities for students to reflect on their own design experience, educators can support students' explicit understanding of the all of the activities (e.g.. iteration, prototyping) that they engage in throughout a design project. Case studies of previous designs in their field can engage students in an analysis of the practice of design and the role of iteration in the success or failure of a design process ${ }^{17}$. Given the multiple types of iteration described by Wynn and colleagues ${ }^{10}$, educators could also design activities focused on increasing students' awareness of the ambiguity that is inherent in design and how different types of iteration that can be used to engage with uncertainty and ambiguity ${ }^{3,25}$. Finally, designing an educational environment for students that encourages risk-taking and play can support students' perception of iteration as a learning activity $^{3,28}$.

Given the focus of this study on aerospace engineering design students, future research should broaden the sample to explore the perceptions of students from different engineering disciplines as well as the perceptions of students engaged in different types of projects (e.g., client-based, service learning). Additionally, longitudinal studies that complement previous work on design behaviors could explore how students' perceptions of iteration and other design activities evolve over the course of their undergraduate career, especially within design educational experiences. In particular, research is needed to better understand how, when, and why students' perceptions of iteration change from viewing iteration as not important to viewing it as an important design activity. Finally, studies could also explore the different definitions of iteration held by not only researchers, but also practitioners and educators from a variety disciplines.

\section{Conclusion}

The purpose of this study was to explore iteration more deeply and uncover students' perceptions about how this aspect of design is related to a broader design process. Students within a senior level aerospace engineering design course at a large public university were given an open ended survey prompt to document their design process mid-way through the course. The resulting design processes illustrated how students perceive iteration explicitly occurring once or not at all during the design process. When iteration did occur, it was most common in the late stages of the process with rare occurrences at the beginning. In addition, the students discussed using iteration to improve the results of mathematical models, as opposed to, for instance, supporting their understanding of the problem. This conception of the use of iteration is a notable departure from experienced designer's conception, which is broader and generally involves series of short and long cycles of iterative design work. The results of this study demonstrate the need for additional research to explore how iteration is defined and how to support students' understanding of the diverse uses of iteration within design.

\section{Acknowledgements}

This material is based upon work supported by the National Science Foundation Graduate Research Fellowship under Grant No. DGE-0644493. The authors would like to thank the 
participants for their time, and Mitchell Cieminski for his valuable feedback about this paper and this study.

\section{References}

${ }^{1}$ Ahmed, S., Wallace, K. M., \& Blessing, L. T. M. (2003). Understanding the differences between how novice and experienced designers approach design tasks. Research in Engineering Design, 14, 1-11.

${ }^{2}$ Atman, C. J., Yasuhara, K., Adams, R. S., Barker, T. J., Turns, J., \& Rhone, E. (2008). Breadth in Problem Scoping: A Comparison of Freshman and Senior Engineering Students. International Journal of Engineering Education, 24(2), 234-245.

${ }^{3}$ Crismond, D. P., \& Adams, R. S. (2012). The Informed Design Teaching and Learning Matrix. Journal of Engineering Education, 101(4), 738-797.

${ }^{4}$ Atman, C. J., Adams, R. S., Cardella, M. E., Turns, J., Mosborg, S., \& Saleem, J. (2007). Engineering Design Processes: A Comparison of Students and Expert Practitioners. Journal of Engineering Education, (October).

${ }^{5}$ Kilgore, D., Atman, C. J., Yasuhara, K., Barker, T. J., \& Morozov, A. (2007). Considering context: A study of firstyear engineering students. Journal of Engineering Education, 96(4), 321-334. Retrieved from http://www.scopus.com/inward/record.url?eid=2-s2.035948963353\&partnerID=40\&md5=94cc9419e80c6857a266086613cdfd89

${ }^{6}$ Adams, R. S., \& Fralick, B. (2010). Work in Progress - A Conceptions of Design Instrument as an Assessment Tool. In 40th ASEE/IEEE Frontiers in Education Conference. Washington, D.C.

${ }^{7}$ Mosborg, S., Adams, R., Kim, R., Atman, C. J., Turns, J., \& Cardella, M. (2005). Conceptions of the Engineering Design Process : An Expert Study of Advanced Practicing Professionals. In American Society for Engineering Education Annual Conference and Exposition (pp. 1-27).

${ }^{8}$ Atman, C. J., Kilgore, D., \& Mckenna, A. (2008). Characterizing Design Learning Through the Use of Language : A Mixed-methods Study of Engineering Designers. Journal of Engineering Education, (July), 310-326.

${ }^{9}$ Oplinger, J. L., \& Lande, M. (2014). Measuring Qualities of Different Engineering Design Process Models : A Critical Review. In American Society for Engineering Education Annual Conference.

${ }^{10}$ Wynn, D. C., Eckert, C. M., \& Clarkson, P. J. (2007). Modelling iteration in engineering design. ICED 2007 International Conference on Engineering Design, (August), 1-12. Retrieved from http://www.designsociety.org/index.php?menu=15\&action=9\&date=2007-08-28

${ }^{11}$ Smith, R. P. (1992). Development and Verification of Engineering Design Iteration Models. Massachusetts Institute of Technology.

${ }^{12}$ Adams, R. S., \& Atman, C. J. (2000). Characterizing Engineering Student Design Processes: An Illustration of Iteration. American Society for Engineering Education, 1-11.

${ }^{13}$ Safoutin, M. J. (2003). A methodology for empirical measurement of iteration in engineering design processes. University of Washington.

${ }^{14}$ Adams, R. S., \& Atman, C. A. (1999). Cognitive processes in iterative design behavior. In Frontiers in Education Conference, 9th Annual.

${ }^{15}$ Butler, W. M. (2012, May). The Impact of Simulation-Based Learning in Aircraft Design on Aerospace Student Preparedness for Engineering Practice: A Mixed Methods Approach. Virginia Polytechnic Institute and State University, Blacksburg, VA.

${ }^{16}$ Hohner, G., Daly, S. R., Wegner, J., Lee, M. K., \& Goldstein, A. F. (2012). Becoming an Engineer: Assessing the impact of a short program on incoming engineering students' understanding of engineering design. In American Society for Engineering Education Annual Conference and Exposition (pp. 1-15). 
${ }^{17}$ Coso, A. E. (2014). Preparing Students to Incorporate Stakeholder Requirements in Aerospace Vehicle Design. Georgia Institute of Technology.

${ }^{18}$ Newstetter, W.C. McCracken, W. M. (2001). Novice conceptions of design: Implications for the design of learning environments. In C. M. Eastman, W. M. McCracken, \& W. Newstetter (Eds.), Design Learning and Knowing: Cognition in Design Education (pp. 63-78). New York: Elsevier.

${ }^{19}$ Oehlberg, L., \& Agogino, A. M. (2011). Undergraduate Conceptions of the Engineering Design Process: Assessing the Impact of a Human-Centered Design Course. In ASEE Annual Conference and Exposition. Vancouver, BC.

${ }^{20}$ Miles, M. B., \& Huberman, A. M. (1994). Qualitative Data Analysis: An Expanded Sourcebook. Sage Publications.

${ }^{21}$ Strauss, A., \& Corbin, J. (1990). Basics of Qualitative Research: Grounded Theory Procedures and Techniques. Newbury Park, CA: Sage Publications.

${ }^{22}$ Constas, M. a. (1992). Qualitative Analysis as a Public Event: The Documentation of Category Development Procedures. American Educational Research Journal, 29(2), 253-266. https://doi.org/10.3102/00028312029002253

${ }^{23}$ Kreber, C., \& Castleden, H. (2008). Reflection on teaching and epistemological structure: reflective and critically reflective processes in "pure/soft" and "pure/hard" fields. Higher Education, 57(4), 509-531. https://doi.org/10.1007/s10734-008-9158-9

${ }^{24}$ Bucciarelli, L. L. (1988). An ethnographic Perspective on Engineering Design. Design Studies, 9(3), 159-168.

${ }^{25}$ Adams, R. S., Turns, J., \& Atman, C. J. (2003). Educating effective engineering designers: The role of reflective practice. Design Studies, 24(3), 275-294. https://doi.org/10.1016/S0142-694X(02)00056-X

${ }^{26}$ Borgford-Parnell, J. L., Deibel, K., \& Atman, C. J. (2010). From engineering design research to engineering pedagogy: bringing research results directly to students. International Journal of Engineering Education2, 26(4), 748-759.

${ }^{27}$ Bailey, R., Szabo, Z., \& Sabers, D. (2004). Assessing Student Learning about Engineering Design in ProjectBased Courses. .

${ }^{28}$ Kelley, T. (2001). The Art of Innovation: Lessons in Creativity from IDEO. New York: Currency Books. 